九州大学学術情報リポジトリ

Kyushu University Institutional Repository

\title{
Microbiological Redox Potential Control to Improve the Efficiency of Chalcopyrite Bioleaching
}

\section{Masaki, Yuse i}

Department of Earth Resources Engineering, Graduate School of Engineering, Kyushu University

Hirajima, Tsuyoshi

Department of Earth Resources Engineering, Graduate School of Engineering, Kyushu University

Sasaki, Keiko

Department of Earth Resources Engineering, Graduate School of Engineering, Kyushu University

Miki, Hajime

Department of Earth Resources Engineering, Graduate School of Engineering, Kyushu University 他

http://hdl. hand le. net/2324/4737396

出版情報：Geomicrobiology Journal. 35 (8)，pp.648-656，2018-04-03. Taylor and Francis バージョン：

権利関係 : 
2 Title: Microbiological Redox Potential Control to Improve the Efficiency of

3 Chalcopyrite Bioleaching

4

5 Yusei MASAKI, Tsuyoshi HIRAJIMA, Keiko SASAKI, Hajime MIKI, Naoko OKIBE*

6

7 Department of Earth Resources Engineering, Graduate School of Engineering, Kyushu

8 University, 744 Motooka, Nishi-ku, Fukuoka 819-0395, Japan

9

$10 \quad{ }^{*}$ Corresponding author

11 Tel. and Fax: + 81928023312

12 E-mail address: okibe@mine.kyushu-u.ac.jp (Naoko Okibe)

15 RUNNING TITLE: Redox potential-controlled bioleaching

16 KEYWORDS: Chalcopyrite bioleaching; moderately thermophilic iron-oxidizers;

17 Solution redox potential $\left(E_{\mathrm{h}}\right)$; bioleaching kinetics 
18 ABSTRACT: The effect of controlling the redox potential $\left(E_{\mathrm{h}}\right)$ on chalcopyrite

bioleaching kinetics was studied as a new aspect of redox control during chalcopyrite

bioleaching, and its mechanism was investigated by employing the "normalized" solution

redox potential $\left(E_{\text {normal }}\right)$ and the reaction kinetics model. Different $E_{\mathrm{h}}$ ranges were

established by use of different acidophiles (Sulfobacillus acidophilus YTF1; Sulfobacillus

sibiricus N1; Acidimicrobium ferrooxidans ICP; Acidiplasma sp. Fv-AP). Cu dissolution

was very susceptible to real-time change in $E_{\mathrm{h}}$ during the reaction. It was found that

efficiency of bioleaching of chalcopyrite can be effectively evaluated on the basis of

$E_{\text {normal, }}$ since it is normalized for real-time fluctuations of concentrations of major metal

solutes during bioleaching. For steady $\mathrm{Cu}$ solubilization during bioleaching at a maximum rate, it was important to maintain a redox potential range of $0 \leq E_{\text {normal }} \leq 1$

$(-0.35 \mathrm{mV}$ optimal) at the mineral surface by employing a "weak" ion-oxidizer. This led to a copper recovery of $>75 \%$. At higher $E_{\text {normal }}$ levels $\left(E_{\text {normal }}>1\right.$ by "strong" microbial mineral surface $(<50 \% \mathrm{Cu}$ recovery) caused by low reactivity of the chalcopyrite and by secondary passivation of the chalcopyrite surface, mainly by jarosite. 
The demand for copper by a number of industrialized and economically emerging nations has been increasing steadily in the last decade. Even though chalcopyrite $\left(\mathrm{CuFeS}_{2}\right)$ ores are generally low-grade and highly refractory, they are an attractive source of copper because they constitute a significant component of porphyry copper deposits [approx. $70 \%$ of the world's copper reserves (Sillitoe, 2010)]. For this reason, a number of studies to improve the copper recovery by overcoming the very slow leaching/bioleaching mechanism of chalcopyrite leaching. the nature of the surface layers is being debated. For instance, it was suggested that the presence of porous $\mathrm{S}^{0}$ layers do not impede the leaching efficiencies significantly (Parker

lixiviants (e.g., $\mathrm{H}_{2} \mathrm{SO}_{4}, \mathrm{HCl}, \mathrm{HClO}_{4}$ with and without $\mathrm{Fe}^{3+}$ ) have been done, no universal agreement on the nature of the chalcopyrite surface has been reached. The presence of elemental sulfur $\left(\mathrm{S}^{0}\right)$, disulfide $\left(\mathrm{S}_{2}{ }^{2-}\right)$; polysulfide $\left(\mathrm{S}^{2-}\right)$ (metal deficient sulfide), Fe oxyhydroxide (jarosite-like species) have been proposed (Li et al. 2013). The leaching of metal sulfide ores was reported to be inhibited by formation of such passivating surface layers (e.g., Stott et al., 2000; Cordoba et al. 2009; Viramontes-Gamboa et al., 2010), but et al. 1981; Antonijevic et al. 1994; Córdoba et al. 2008, 2009). Such diversity in findings 
is often caused by differences in experimental conditions (e.g., $\mathrm{pH}$, temperature, solute concentration (Li et al., 2013).

Nonetheless, it is generally understood that one of the most important parameters governing bioleaching is the redox potential of the leaching solution $\left(E_{\mathrm{h}}\right)$ : From a review of a number of electrochemical, chemical, and biological studies, Viramonetes-Gamboa et al. $(2007 ; 2010)$ suggested that chalcopyrite leaching with ferric sulfate is in its active state at $<685 \mathrm{mV}$ (SHE), regardless of impurities in the chalcopyrite, or the acidity or the temperature of the reaction. At $685-755 \mathrm{mV}$ (SHE), chalcopyrite is in a bistable system (it could be passive or active depending on how it was brought to that potential). At $>755$ $\mathrm{mV}$ (SHE), chalcopyrite leaching is in the passive state with a strong passivation effect.

Based on some electrochemical/chemical leaching studies, Hiroyoshi et al. (2000, 2001, 2004, 2008a, b) proposed a mechanism of chalcopyrite dissolution controlled by $E_{\mathrm{h}}$ levels. According to this mechanism, chalcopyrite leaching using ferric sulfate is enhanced by the presence of $\mathrm{Fe}^{2+}$ and $\mathrm{Cu}^{2+}$, leading to the formation of intermediate chalcocite $\left(\mathrm{Cu}_{2} \mathrm{~S}\right)$ owing to the low $E_{\mathrm{h}}$ from the presence of $\mathrm{Fe}^{2+}(1)$. The oxidation of $\mathrm{Cu}_{2} \mathrm{~S}$ then yields $\mathrm{Cu}^{2+}(2)$ :

$\mathrm{Cu}^{I} \mathrm{Fe}^{I I I} \mathrm{~S}^{-I I} 2$ (chalcopyrite) $+3 \mathrm{Cu}^{2+}+3 \mathrm{Fe}^{2+} \rightarrow 2 \mathrm{Cu}_{2}{ }_{2} \mathrm{~S}^{-I I}($ chalcocite $)+4 \mathrm{Fe}^{3+}$ $\Delta G^{0}=35.0 \mathrm{~kJ} / \mathrm{mol}^{-1}$

$$
\mathrm{Cu}_{2} \mathrm{~S} \text { (chalcocite) }+4 \mathrm{Fe}^{3+} \rightarrow 2 \mathrm{Cu}^{2+}+\mathrm{S}^{0}+4 \mathrm{Fe}^{2+}
$$


$\Delta G_{2}{ }^{0}=-81.1 \mathrm{~kJ} / \mathrm{mol}^{-1}$

Copper recoveries are enhanced when $E_{\mathrm{ox}}<E_{\mathrm{h}}<E_{\mathrm{c}}$ is satisfied (with an optimal potential of $630 \mathrm{mV}$ (SHE); Hiroyoshi et al. 2000, 2008a), where;

$E_{\mathrm{c}}$ ("critical potential") is the equilibrium redox potential of the formation of the intermediate chalcocite from chalcopyrite $\left(E_{\mathrm{c}}(\mathrm{V})=E_{\mathrm{c}}^{0}+\frac{\mathrm{RT}}{4 \mathrm{~F}} \ln \frac{\left(a_{\left.\mathrm{Cu}^{2+}\right)^{3}}\right.}{a_{F e^{2+}}}\right)$

$E_{\text {ox }}$ ("oxidation potential") is the equilibrium redox potentials of the subsequent oxidation of chalcocite to $\mathrm{Cu}^{2+}\left(E_{\mathrm{ox}}(\mathrm{V})=E_{\mathrm{ox}}^{0}+\frac{\mathrm{RT}}{4 \mathrm{~F}} \ln \left(a_{\mathrm{Cu}^{2+}}\right)^{2}\right)$

Since bioleaching is an economic approach for processing highly refractory chalcopyrite ores/concentrates, it is important to investigate the applicability of the above reactions (1) through (4) to this process. Previously, Gerricke et al. (2010) and Ahmadi et al. $(2010,2011)$ reported on maximizing $\mathrm{Cu}$ extraction from chalcopyrite at $600-650 \mathrm{mV}$ (SHE) by suppression of pyrite oxidation, thereby preventing jarosite formation. The aim of the present study was set to achieve a more comprehensive understanding of the mechanism of chalcopyrite leaching. Furthermore, microbiological $E_{\mathrm{h}}$ control instead of electrochemical/chemical control began to be studied as a new aspect of redox control of chalcopyrite bioleaching. Specific aims of the present study were (i) evaluation of the effect of "microbiological redox control" on chalcopyrite leaching through application of specific Fe-oxidizing microorganisms, and (ii) elucidation of the mechanism of chalcopyrite bioleaching in terms of reaction kinetics under specified low redox 
potentials by considering the concept of $E_{\text {normal. }}$

\section{Materials and Methods}

Microorganisms

Five moderately thermophilic, acidophilic strains were used: (i) Fe-oxidizers; three bacterial species (Sulfobacillus acidophilus YTF1; Sb. sibiricus N1 ${ }^{\mathrm{T}}$ (DSM 17363); Acidimicrobium ferrooxidans $\mathrm{ICP}^{\mathrm{T}}$ (DSM 10331)) and one archaeal species (Acidiplasma sp. Fv-Ap), (ii) S-oxidizer; Acidithiobacillus (At.) caldus $\mathrm{KU}^{\mathrm{T}}$ (DSM 8584). The five strains were maintained and pre-grown aerobically at $45^{\circ} \mathrm{C}$ in heterotrophic basal salts (HBS) medium (Masaki et al. 2015; pH 1.5) supplemented with $0.01 \%\left(\mathrm{w} \mathrm{v}^{-1}\right)$ yeast extract (YE). Ten-millimolar $\mathrm{Fe}^{2+}\left(\right.$ as $\left.\mathrm{FeSO}_{4} \cdot 7 \mathrm{H}_{2} \mathrm{O}\right)$ and $0.1 \%\left(\mathrm{w} \mathrm{v}^{-1}\right) \mathrm{S}^{0}$ plus trace caldus $\mathrm{KU}$, respectively. All $\mathrm{pH}$ adjustments in this work were made with $\mathrm{H}_{2} \mathrm{SO}_{4}$.

\section{Mineral}

Chalcopyrite concentrate (20-106 $\mu \mathrm{m}$; JX Nippon Mining \& Metals) was washed with 1 $\mathrm{M} \mathrm{HNO}_{3}$, deionized water and $100 \%$ ethanol before freeze-drying overnight. The elemental composition (Table

I) was calculated from the ICP measurement after a hydrothermal pre-treatment in aqua regia $\left(5 \mathrm{~g} \mathrm{~L}^{-1}\right)$ using Ethos Plus computerized 
110 microwave labstation (Milestone General; $50 \mathrm{~Hz}$; heated to $220^{\circ} \mathrm{C}$ in $8^{\circ} \mathrm{C}$ increments per minute, kept at $220^{\circ} \mathrm{C}$ for $15 \mathrm{~min}$, and finally allowed to cool to room temperature). The concentrate consisted mainly of chalcopyrite with pyrite as minor constituent (Figure 5).

\section{Comparison of $\mathrm{Fe}^{2+}$-oxidizing abilities of different microbial strains}

One-hundred milliliter flasks containing 50 mL HBS medium $\left(\mathrm{pH} 2.0 ;+0.01 \% \mathrm{~S}^{0} ;+10\right.$ $\mathrm{mM} \mathrm{Fe}{ }^{2+} ;+\mathrm{TE} ; \pm 0.01 \%$ YE) were inoculated with mixed culture containing At. caldus sibiricus N1, Am. ferrooxidans ICP or Acidiplasma sp. Fv-AP; $1 \times 10^{7}$ cells $\mathrm{mL}^{-1}$ ). The

\section{Chalcopyrite Bioleaching}

Five-hundred milliliter flasks containing $200 \mathrm{~mL}$ HBS medium $\left(\mathrm{pH} 2.0 ;+1 \%\left(\mathrm{w} \mathrm{v}^{-1}\right)\right.$ chalcopyrite concentrate; $\left.+0.01 \% \mathrm{~S}^{0} ;+5 \mathrm{mM} \mathrm{Fe}^{2+} ;+\mathrm{TE}\right)$ were inoculated with mixed culture containing At. caldus $\mathrm{KU}\left(1 \times 10^{7}\right.$ cells $\left.\mathrm{mL}^{-1}\right)$ plus one of the four Fe-oxidizers $\left(1 \times 10^{7}\right.$ cells $\left.\mathrm{mL}^{-1}\right)$. Mixed cultures containing Am. ferrooxidans ICP and Acidiplasma sp. Fv-Ap were prepared with or without $0.01 \%$ YE. The flasks were incubated at $45^{\circ} \mathrm{C}$, 
129 shaken at $150 \mathrm{rpm}$. Sterile controls were run in parallel. Samples were regularly taken for

130 solution analyses (as described below) (water evaporation was compensated with

131 deionized water prior to sampling).

\section{Characterization of bioleaching residues over time}

134 Mixed cultures containing Sb. sibiricus N1 plus At. caldus KU were prepared (as described above) in nine-fold to monitor overtime changes in characteristics of

136 bioleached chalcopyrite concentrate residues. Liquid samples were taken for solution analyses prior to collecting the bioleached residues.

\section{Solution and Solid Analyses}

140 Cell density was monitored by direct counting (Thoma chamber). Liquid samples were

141 first filtered $(0.20 \mu \mathrm{m})$ to determine concentrations of $\mathrm{Fe}^{2+}$ (o-phenanthroline method;

142 Caldwell et al. 1946) and total dissolved Fe/Cu (ICP-AES; SEIKO Vista-MPX). Eh values were measured with an $\mathrm{Ag} / \mathrm{AgCl}$ reference electrode (with an automatic conversion to SHE) (MM-60R, TOADKK). overnight and analyzed by X-ray diffraction (XRD) (Ultima IV, Rigaku; CuKa $40 \mathrm{~mA}$, 
spectroscopy (XPS) (ESCA 5800, ULVAC-PHI; Al $\mathrm{K} \alpha$ ) and electron probe micro analyzer (EPMA) (JEOL JXA-8530F; $10 \mathrm{nA}, 20 \mathrm{kV})$.

\section{Results and Discussion}

\section{Solution Redox Potentials $\left(E_{\mathrm{h}}\right)$ Exhibited by Different Fe-oxidizing Microbes}

To screen the conditions for the next bioleaching test, changes in $\mathrm{Fe}^{2+}$ concentration, 10 $\mathrm{mM}$ initially, and in $E_{\mathrm{h}}$ over time in each mixed culture (At. caldus plus one of the four Fe-oxidiaers; i.e. Sb. acidophilus YTF1, Sb. sibiricus N1, Am. ferrooxidans ICP or Acidiplasma sp. Fv-AP) were determined. The Effect of $0.01 \%$ YE on mixotrophic/heterotrophic $\mathrm{Fe}^{2+}$ oxidation was also evaluated.

Am. ferrooxidans ICP was the strongest Fe-oxidizer of the group, leading to the quick establishment of higher $E_{\mathrm{h}}$ values $(>800 \mathrm{mV}$ ) by day 2 . Addition of YE slightly enhanced $\mathrm{Fe}^{2+}$ oxidation and cell growth (Figure 1b, c). In the mixed culture with $S b$. sibiricus N1, YE addition caused a rapid rise in $E_{\mathrm{h}}$ to $\sim 800 \mathrm{mV}$ but did not affect cell density significantly (Fig. 1c). $\mathrm{Fe}^{2+}$ oxidation by Acidiplasma sp. Fv-Ap was slower than that by the former two strains (Am. ferrooxidans ICP and Sb. sibiricus N1), but it generated higher $E_{\mathrm{h}}$ levels $(\sim 800 \mathrm{mV})$ after day 6 (Fig. 1b). In contrast, a constantly low $E_{\mathrm{h}}$ level $(<600 \mathrm{mV})$ was maintained in Sulfobacillus sp. YTF1 cultures with or without YE addition, due to only minor $\mathrm{Fe}^{2+}$ oxidation by the strain (Figure 1a). 
selecting the following conditions: i.e., Mixed cultures containing At. caldus KU plus one

of the following Fe-oxidizers; Sb. acidophilus YTF1 (-YE), Sb. sibiricus N1 (-YE),

Acidiplasma sp. Fv-Ap ( \pm YE) or Am. ferooxidans ICP (+YE).

\section{Fe-oxidizers}

Chalcopyrite Bioleaching at Redox Potentials $\left(E_{h}\right)$ Generated by Different Rapid $\mathrm{Fe}^{2+}$ oxidation was observed with Am. ferrooxidans ICP and Acidiplasma sp. Fv-Ap in the presence of YE (Figure 2d), accompanied by an immediate increase in $E_{\mathrm{h}}$ ( $>800$ and $750 \mathrm{mV}$, respectively; Figure $2 \mathrm{~b}$ ), and an increase in cell density (up to $7 \times 10^{8}$ cells $\mathrm{mL}^{-1}$ ), compared to other cultures (Figure 2f). At the same time, less chalcopyrite dissolution was noted with these two strains (Figure 2a, c) than with the others tested. Am. ferrooxidans ICP is able to grow autotrophically on $\mathrm{Fe}^{2+}$ and heterotrophically on YE (Clark and Norris, 1996). The genus Acidiplasma is able to oxidize $\mathrm{Fe}^{2+}$ in the presence of trace amount of YE (Golyshina et al. 2009). Therefore, YE promoted strong heterotrophic $\mathrm{Fe}^{2+}$ oxidation by the two strains with an immediate rise in $E_{\mathrm{h}}$. In the absence of YE, a 14-day lag was followed by rapid $\mathrm{Fe}^{2+}$ oxidation by Acidiplasma sp. Fv-Ap (Fig. 2d), leading to a sudden increase in $E_{\mathrm{h}}$ on day 14 (Fig. 2b). Thus, chalcopyrite dissolution started off rapidly, and then slowed after day 14 (Figure 2a, c), a 
clear transition in $E_{\mathrm{h}}$ levels from $550-600 \mathrm{mV}$ to $\geq 700 \mathrm{mV}$ (Figure $2 \mathrm{~b}$ ). With $S b$.

sibiricus $\mathrm{N} 1, \mathrm{Fe}^{2+}$ oxidation became extensive only after day 29 (Figure 2d), creating a

clear transition in $E_{\mathrm{h}}$ levels from $550-600 \mathrm{mV}$ to $>700 \mathrm{mV}$ (Figure 2b). Chalcopyrite

dissolution readily progressed until the $E_{\mathrm{h}}$ level came to this transition (Figure 2a, c). $S b$.

acidophilus YTF1 showed the weakest $\mathrm{Fe}^{2+}$ oxidation throughout (Figure 2d) and $E_{\mathrm{h}}$

values remained stable at around $600 \mathrm{mV}$ (Figure 2b). As a result, dissolution of $\mathrm{Cu}$ and

Fe progressed continuously for 70 days (Figure $2 \mathrm{a}$, c). Relatively higher $\mathrm{pH}$ values

(Figure 2e) shown in Sb. acidophilus YTF1, Sb. sibiricus N1, and Acidiplasma sp. Fv-Ap

(-YE; only at the beginning) cultures are indicative of greater $\mathrm{H}^{+}$-consuming chalcopyrite dissolution that counteracting sulfuric acid production by At. caldus KU (Figure 2a, c).

Microscopic observation of morphological differences between At. caldus KU (smaller rods) and Sb. acidophilus YTF1 cells (larger and longer rods), or between At. caldus KU (larger rods) and Acidisplasma sp. Fv-Ap cells (smaller irregular cocci) showed that At. caldus KU dominated by cell count initially, followed by emergence and gradual increase of respective Fe-oxidizing cells. This observation suggests that autotrophic growth of At. caldus KU on $\mathrm{S}^{0}$ (Hallberg and Lindstörm, 1994) occurred first, producing cell exudates/lysates of organics that supported subsequent growth of mixotrophic/heterotrophic Fe-oxidizers. Since steady growth of Sb. sibiricus N1 is only possible by simultaneous utilization of inorganic substrates (e.g., $\left.\mathrm{Fe}^{2+}, \mathrm{S}^{0}\right)$ and organic 
substrates (e.g., yeast extract) (Melamud et al. 2003), sudden initiation of active $\mathrm{Fe}^{2+}$

oxidation by Sb. sibiricus N1 on day 36 (Figure 2d) was probably the result of

accumulation of the organic substrates. Likewise, the heterotrophic $\mathrm{Fe}^{2+}$ oxidation by Acidiplasma sp. Fv-Ap on day 14 (Figure 2d) was probably the result of release of organics by the autotrophic organisms. Growth of Sb. acidophilus YTF1 was reported to occur both autotrophically (on $\mathrm{Fe}^{2+} / \mathrm{S}^{0}$ ) and heterotrophically (on yeast extract), although $\mathrm{Fe}^{2+}$ oxidation was more rapid and complete in the presence of yeast extract (Norris et al. 1996). Unlike $S b$. sibiricus $\mathrm{N} 1$ and Acidiplasma sp. Fv-Ap, weak $\mathrm{Fe}^{2+}$ oxidation by $S b$. acidophilus YTF1 continued steadily. This difference may be due partly to the metabolic inefficiency in utilizing the organic substrates derived from the autotrophs.

The above results indicate that different $E_{\mathrm{h}}$ levels can be created by selected Fe-oxidizers in the bioleaching system. Chalcopyrite dissolution was highly susceptible to the real-time change in $E_{\mathrm{h}}$ and maintaining lower $E_{\mathrm{h}}$ values facilitated a constant $\mathrm{Cu}$ solubilization.

\section{Correlation Between Cu Recovery and Normalized Solution Redox Potentials}

\section{( $\left.E_{\text {normal }}\right)$ During Bioleaching}

Until now, only relatively limited studies have examined the effect of controlling $E_{\mathrm{h}}$ of bioleaching systems: Running an electrochemical bioleaching reactor at $600-630 \mathrm{mV}$ 
224 (SHE) resulted in improvement of chalcopyrite leaching when compared to results from conventional bioleaching, chemical leaching and electrochemical leaching. This can be concentrations achieved by electrochemical $\mathrm{Fe}^{3+}$ reduction to $\mathrm{Fe}^{2+}$, and (c) to electro-reduction of chalcopyrite to produce less refractory chalcocite and covellite (Ahmadi et al 2010, 2011). Improved chalcopyrite bioleaching was also observed by controlling $E_{\mathrm{h}}$ at $580 \mathrm{mV}$ (SHE) (Third et al. 2002) or at $620 \mathrm{mV}$ (SHE) (Gericke et al. 2010) through arresting the oxygen supply.

From previous chemical leaching studies, experimental conditions such as metal ion concentrations, solid/liquid ratios and co-existing minerals were shown to affect the optimal $E_{\mathrm{h}}$ value for $\mathrm{Cu}$ extraction (Okamoto 2004, 2005; Hiroyoshi 2008a, 2008b). This could cause misleading interpretation of results obtained from different studies conducted under different conditions. In order to define the optimal $E_{\mathrm{h}}$ value independent of such conditional differences, "the normalized redox potential $\left(E_{\text {normal }}\right)$ " was proposed for a reaction model assuming the formation of intermediate $\mathrm{Cu}_{2} \mathrm{~S}$ from chalcopyrite, with its optimal range being $0 \leq E_{\text {normal }} \leq 1$ (highest copper extraction rate achieved at $E_{\text {normal }} \approx$ 0.43; Okamoto et al. 2004, 2005; Hiroyoshi et al. 2008a, 2008b):

$E_{\text {normal }}=\left(E_{\mathrm{h}}-E_{\mathrm{ox}}\right) /\left(E_{\mathrm{c}}-E_{\mathrm{ox}}\right)$ A reaction model based on $E_{\text {normal }}$ has yet to be discussed in detail for bioleaching 
studies. We are using the data in Figure 2 of this study to evaluate the effectiveness of the

bioleaching reaction based on $E_{\text {normal }}$ to reflect real-time concentrations of $\mathrm{Fe}^{2+}$ and $\mathrm{Cu}^{2+}$,

using equations 3, 4, and 5 in Figure 3.

With Acidiplasma sp. Fv-Ap and Am. ferrooxidans ICP (+YE), Enormal rapidly rose to

$1\left(E>E_{\mathrm{c}}\right)$ due to prompt microbial $\mathrm{Fe}^{2+}$ oxidation. The intermediate $\mathrm{Cu}_{2} \mathrm{~S}$ does not

Sb. sibiricus N1 and Acidiplasma sp. Fv-Ap cultures (-YE) displayed a transition in the $E_{\text {normal }}$ level from $0 \leq E_{\text {normal }} \leq 1$ to $E_{\text {normal }}>1$. This clearly corresponded to the trend of $\mathrm{Cu}$ extraction behavior: The $E_{\text {normal }}$ values stayed within the optimal range ( $0 \leq E_{\text {normal }}$ $\leq 1$ ) for a longer period in the Sb. sibericus N1 cultures than in the Acidiplasma sp. Fv-Ap cultures, resulting in greater $\mathrm{Cu}$ recovery in the former $(77 \%)$ than in the latter (59\%) (Fig 2b, c). In sterile controls, copper leaching slowed as $E_{\text {normal }}$ approached 0. This was because $E_{\text {normal }}<0\left(E_{\mathrm{ox}}>E_{\mathrm{h}}\right)$ indicates a "non-reactive region" (Hiroyoshi et al. 2008a, b) in which $\mathrm{Cu}_{2} \mathrm{~S}$ is not oxidized and $\mathrm{Cu}$ extraction ceases. The final $\mathrm{Cu}$ recovery 
in sterile controls was 20\% (Figure $2 \mathrm{f}$ ).

Overall, the results suggest that efficiency of chalcopyrite bioleaching can be

264 effectively evaluated by incorporating $E_{\text {normal }}$ as a valuation basis which is independent of

the real-time change in major metal solutes in the system. The relationship between the

$\mathrm{Cu}$ leaching rate and $E_{\text {normal }}$ is summarized in Figure 4. The maximum $\mathrm{Cu}$ leaching rate

was achieved at around $E_{\text {normal }}=0.35$. The optimum $E_{\text {normal }}$ value of 0.43 , originally reported by Hiroyoshi et al. (2008a, 2008b), was shifted to slightly lower value in this study. This difference may have been caused partly by the higher $\left(45^{\circ} \mathrm{C}\right)$ temperature used in this study compared to ambient temperature of $30^{\circ} \mathrm{C}$ (Hiroyoshi et al. 2008a, 2008b), facilitating the kinetics of chalcocite-intermediate reactions at even lower $E_{\mathrm{h}}$ levels. Another possible explanation is involvement of microbial reactions in this study, compared to abiotic chemical leaching studies (except for one kind of experiment using a mesophilic Fe-oxidizing bacterium) by Hiroyoshi et al. (2008a, b). Thus, (i) Fe-oxidizing microbes generate an Fe-cycle by which they promote chalcocite/covellite oxidation while simultaneously maintaining lower $E_{\text {normal }}$ values. (ii) The $\mathrm{S}^{0}$, a by product of covellite oxidation, is also solubilized by $\mathrm{S}^{0}$-oxidizing cells, which shifts the chemical equilibrium in favor of covellite dissolution. The above microbially mediated covellite dissolution processes ( $\mathrm{i}$ and ii) may also lower the optimal $E_{\text {normal }}$ value slightly in bioleaching compared to chemical leaching. 
Changes in Residues During Bioleaching of Chalcopyrite Concentrate with Mixed

\section{Cultures Containing Sb. sibiricus N1 and At. caldus KU}

Each flask was incubated until day 2, 7, 12, 21, 26, 31, 38, 55 and 70 to collect all of the

bioleached residues remaining in the flask. $\mathrm{Cu}$ dissolution and $E_{\text {normal }}$ behaviors were

this experiment were indicated by overlapping Figure $3 \mathrm{~b}$.

( $E_{\text {normal }}>\sim 0.6$; Figure $3 \mathrm{~b}$ ), accompanied by distinctive color change of the mineral to

yellow (Figure 5). XPS peaks of $\mathrm{Cu} 2 \mathrm{p}_{3 / 2} / \mathrm{Cu} 2 \mathrm{p}_{1 / 2}$ (Figure 6a) and $\mathrm{S} 2 \mathrm{p}_{3 / 2} / \mathrm{S} 2 \mathrm{p}_{1 / 2}$

(Figure 6b) derived from the original chalcopyrite concentrate were observed in

bioleached residues until day 31 . Sulfate $S 2 p$ peaks emerged at day 38 . Together with the

XRD results, surface-sensitive XPS analyses indicate formation of passivation layers

with declining $\mathrm{Cu}$ dissolution after day 38 (Figure $3 \mathrm{~b}$ ).

according to the following two-step reaction;

$\mathrm{Cu}_{2} \mathrm{~S}$ (chalcocite) $\rightarrow \mathrm{Cu}_{2-x} \mathrm{~S}+x \mathrm{Cu}^{2+}+2 x \mathrm{e}^{-} \quad(0<x \leq 1)$

$\mathrm{CuS}($ covellite $) \rightarrow \mathrm{Cu}^{2+}+\mathrm{S}^{0}+2 \mathrm{e}^{-}$ 
300 Since covellite dissolution is slower than that of chalcocite (Gupta 2003), covellite may

301 be more readily detected during chalcopyrite leaching: In fact, other researchers detected covellite (rather than chalcocite) in bioleached and chemically-leached chalcopyrite residues via Raman spectroscopy (Sasaki et al. 2009) and XRD patterns (Córdoba et al. 2008), respectively. In this study, no direct evidence for intermediate chalcocite or covellite was obtained (by XRD, XAFS, EPMA and XPS; data not shown). Since the original chalcopyrite concentrate contained a minor amount of blue-colored covellite (by especially at $E_{\text {normal }}>1$ (Fig. 4), were caused by the low reactivity of chalcopyrite at high $E_{\mathrm{h}}$ (Hiroyoshi et al. 2004) and by the passivation mainly due to jarosite that occurred on the chalcopyrite surface. 
319 Mineral dissolution is most frequently interpreted in terms of a shrinking core model.

320 Such fluid-solid reaction may be generally described as follows:

$321 \quad A_{\text {(fluid) }}+b B$ (solid) $\rightarrow c \mathrm{C}_{\text {(fluid) }}+d \mathrm{D}$ (solid)

In this model, the overall reaction proceeds via diffusion through a liquid film (9),

diffusion through a product layer (10), and surface chemical reaction (11), one of which

steps becomes rate-limiting under certain conditions (Sohn and Wadsworth, 1979):

$X=k_{1} t$

$1-3(1-X)^{2 / 3}+2(1-X)=k_{d} t$

$1-(1-X)^{1 / 3}=k_{\mathrm{r}} t$

acidophilus YTF1 cultures (Figure 7a; Table II), where $0 \leq E_{\text {normal }} \leq 1$ was satisfied 
throughout the bioleaching period (Figure 3a). A similar trend was found with $S b$.

sibiricus N1 cultures, but only until day 44 (Figure 7a; Table II); this was consistent with

$0 \leq E_{\text {normal }} \leq 1$ having being satisfied until day 44 (Figure $3 b$ ).

With Acidiplasma sp. Fv-Ap (-YE), the initial bioleaching phase (until day 10)

appeared to be controlled by a surface chemical reaction, whereas subsequent phases

appeared to be controlled by diffusion through the product film (Figure 7b; Table II).

This corresponded to the major shift in the $E_{\text {normal }}$ level at around day 12 from $0 \leq E_{\text {normal }}$

$\leq 1$ to $E_{\text {normal }}>1$ (Figure $3 b$ ). The $E_{\text {normal }}$ level immediately jumped to $>1$ in Acidiplasma

sp. Fv-Ap and Am. ferrooxidans ICP cultures (+YE) (Figure 3d and 3e, respectively). In 
different results suggesting different kinetic mechanism of chalcopyrite leaching. Thus,

whereas chemical leaching with non- $\mathrm{Fe}^{3+}$ oxidants resulted in dissolution of chalcopyrite

controlled by chemical reaction, chemical leaching with $\mathrm{Fe}^{3+}$ proceeded through product

layer-controlled chalcopyrite dissolution because of passivation of the chalcopyrite

surface by jarosite deposition (Dutriziac et al. 1969, 1981). It should be noted that

deposition of secondary $\mathrm{S}^{0}$ at the chalcopyrite surface did not cause diffusion resistance

(Antonijevic et al. 1994, 2004; Adebayo et al. 2003; Mahajan et al. 2007). However, at

fixed $\mathrm{pH}, E_{\mathrm{h}}$ and temperature, it appears most likely that $\mathrm{Fe}^{3+}$ leaching is surface reaction

rate-controlled during the initial stage, which is later controlled by surface layer diffusion

chalcopyrite leaching enabled a reaction controlled by surface chemical reaction in ferric sulfate media (Córdoba et al. 2008).

In the case of bioleaching, $\mathrm{Fe}^{3+}$ is the essential oxidant in the system. Even though reaction being controlled by diffusion through product film (Pradhan et al. 2010; 
Consideration of the results of this study and the above-mentioned previous

observations leads to the conclusion that the rate-limiting step of chalcopyrite dissolution depends greatly on the $E_{\mathrm{h}}$ value, which fluctuates continually during bioleaching. It was found that efficiency of bioleaching of chalcopyrite could be evaluated on the basis of $E_{\text {normal. }}$ Controlling the optimal $E_{\mathrm{h}}$ level (to satisfy $0 \leq E_{\text {normal }} \leq 1$; especially at $E_{\text {normal }}=$ $\sim 0.35$ at $45^{\circ} \mathrm{C}$ ) in bioleaching systems is thus critical for promoting steady $\mathrm{Cu}$ solubilization by a surface chemical reaction. This was possible by selecting a suitable Fe-oxidizing microbe. No physicochemical/electrochemical manipulation was needed. In actual bioleaching operations, however, a range of indigenous Fe-oxidizing microbes are present on the mineral surface. In order to microbiologically maintain a low

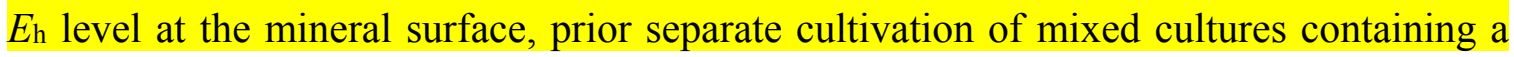
"weak" Fe-oxidizer and subsequent inoculation of the ore would be necessary to make it the dominant Fe-oxidizing species in the system. Inclusion of minerals such as $\mathrm{PbS}$ that are inhibitory to some microbes (Vilcáez 2015) is a possible means of selectively favoring the growth of weak Fe-oxidizers or of suppressing the activity of indigenous strong Fe-oxidizers. Acidophilic microbes also display different degrees of sensitivity to flotation agents (Okibe and Johnson 2002), which could be exploited in favoring selective growth of preferred Fe-oxidizers in a leaching operation. Further optimization is ongoing to maximize the controlling effect of low redox potential on bioleaching of chalcopyrite 
395 concentrate. The utility of the findings of this study is also currently under evaluation

396 using low grade $(<1 \%)$ chalcopyrite ores.

397 


\section{References}

399 Abhilash GA, Mehta KD, Pandey BD. 2013. Bacterial leaching kinetics for copper 400 dissolution from a low-grade Indian chalcopyrite ore. Rem: Rev Esc Minas 66:245-250.

Abhilash GA, Pandey BD. 2015. Bioleaching of low grade granitic chalcopyrite ore by hyperthermophiles: Elucidation of kinetics-mechanism. Metall Res Technol 112:506.

Adebayo AO, Ipinmoroti KO, Ajayi OO. 2003. Dissolution kinetics of chalcopyrite with hydrogen peroxide in sulphuric acid medium. Chem Biochem Eng Q 17:213-218.

407

Ahmadi A, Schaffie M, Manafi Z, Ranjbar M. 2010. Electrochemical bioleaching of high 104:99-105.

Ahmadi A, Schaffie M, Petersen J, Schippers A, Ranjbar M. 2011. Conventional and electrochemical bioleaching of chalcopyrite concentrates by moderately thermophilic bacteria at high pulp density. Hydrometallurgy 106:84-92.

416 Antonijević MM, Janković Z, Dimitrijević M. 1994. Investigation of the kinetics of 
417 chalcopyrite oxidation by potassium dichromate. Hydrometallurgy 35:187-201.

419 Antonijević MM, Janković ZD, Dimitrijević MD. 2004. Kinetics of chalcopyrite 420 dissolution by hydrogen peroxide in sulphuric acid. Hydrometallurgy 71:329-334.

Boekestein A, Stadhouders AM, Stols ALH, Roomans GM. 1983. A comparison of ZAF-correction methods in quantitative X-ray microanalysis of light-element specimens.

Ultramicroscopy 12:65-68.

Caldwell DH, Adams RB. 1946. Colorimetric determination of iron in water with

$o$-phenanthroline. J Am Water Works Ass 38:727-730.

Clark DA, Norris PR. 1996. Acidimicrobium ferrooxidans gen. nov., sp. nov.: mixed-culture ferrous iron oxidation with Sulfobacillus species. Microbiology 142:785-790. chalcopyrite during its chemical leaching with ferric ion at $68^{\circ} \mathrm{C}$. Miner Eng 22:229-235. 
436 Córdoba EM, Muñoz JA, Blázquez ML, González F, Ballester A. 2008a. Leaching of chalcopyrite with ferric ion. Part II: Effect of redox potential. Hydrometallurgy 93:88-96.

439 Córdoba EM, Muñoz JA, Blázquez ML, González F, Ballester A. 2008b. Leaching of 440 chalcopyrite with ferric ion. Part IV: The role of redox potential in the presence of 441 mesophilic and thermophilic bacteria. Hydrometallurgy 93:106-115. media. Metall Trans B 12B:371-378.

DutrizacJE, MacDonald JC, Ingraham TR. 1969. The kinetics of dissolution of synthetic chalcopyrite in aqueous acidic ferric sulphate solution. T Metall Soc Aime 245:955-959. concentrates using redox control. Hydrometallurgy 104:414-419.

Ghahremaninezhad A, Dixon DG, Asselin E. 2013. Electrochemical and XPS analysis of chalcopyrite $\left(\mathrm{CuFeS}_{2}\right)$ dissolution in sulfuric acid solution. Electrochim Acta 87:97-112. 
455 Golyshina OV, Yakimov MM, Lünsdorf H, Ferrer M, Nimtz M, Timmis KN, Wray V,

456 Tindall BJ, Golyshin PN. 2009. Acidiplasma aeolicum gen. nov., sp. nov., a euryarchaeon

457 of the family Ferroplasmaceae isolated from a hydrothermal pool, and transfer of

458 Ferroplasma cupricumulans to Acidiplasma cupricumulans comb. nov. Int J Syst Evol

459 Microbiol 59:2815-2823.

460

461 Gupta CK. 2003. Chemical Metallurgy: Principles and Practice. Weinheim: Wiley-VCH

462 Verlag GmbH \& Co. KGaA. 842p.

Hallberg KB, Lindström EB. 1994. Characterization of Thiobacillus caldus sp. nov., a moderately thermophilic acidophile. Microbiology 140:3451-3456.

Hydrometallurgy 91:144-149.

Hiroyoshi N, Kuroiwa S, Miki H, Tsunekawa M, Hirajima T. 2004. Synergistic effect of

Hiroyoshi N, Kitagawa H, Tsunekawa M. 2008a. Effect of solution composition on the optimum redox potential for chalcopyrite leaching in sulfuric acid solutions. cupric and ferrous ions on active-passive behavior in anodic dissolution of chalcopyrite in sulfuric acid solutions. Hydrometallurgy 74:103-116. 
475 Hiroyoshi N, Miki H, Hirajima T, Tsunekawa M. 2000. A model for ferrous-promoted 476 chalcopyrite leaching. Hydrometallurgy 57:31-38.

Hiroyoshi N, Miki H, Hirajima T, Tsunekawa M. 2001. Enhancement of chalcopyrite 47:253-258.

Process 62:65-94. 
Mahajan V, Misra M, Zhong K, Fuerstenau MC. 2007. Enhanced leaching of copper

from chalcopyrite in hydrogen peroxide-glycol system. Miner Eng 20:670-674.

495

Masaki Y, Hirajima T, Sasaki K, Okibe N. 2015. Bioreduction and immobilization of hexavalent chromium by the extremely acidophilic $\mathrm{Fe}(\mathrm{III})$ reducing bacterium Acidocella aromatica strain PFBC. Extremophiles 19:495-503.

Masaki Y, Tsutsumi K, Hirano S, Okibe N. 2016. Microbial community profiling of

Chinoike Jigoku ("Blood Pond Hell") hot spring in Beppu, Japan and isolation and 167:595-603.

Melamud VS, Pivovarova TA, Tourova TP, Kolganova TV, Osipov GA, Lysenko AM, 506 thermophilic bacterium. Microbiology 72:605-612.

509 Norris PR, Clark DA, Owen JP, Waterhouse S. 1996. Characteristics of Sulfobacillus 510 acidophilus sp. nov. and other moderately thermophilic mineral-sulphide-oxidizing bacteria. Microbiology 142:775-783. 
513 Okamoto H, Nakayama R, Hiroyoshi N, Tsunekawa M. 2004. Redox potential 514 dependence and optimum potential of chalcopyrite leaching in sulfuric acid solutions. 515 Journal of MMIJ 120:592-599 (in Japanese).

Okamoto H, Nakayama R, Kuroiwa S, Hiroyoshi N, Tsunekawa M. 2005. Normalized redox potential used to assess chalcopyrite column leaching. Journal of MMIJ 121:246-254 (in Japanese).

bioleaching microorganisms. Biotechnol Lett 24:2011-2016.

Parker AJ, Paul RL, Power GP. 1981. Electrochemistry of the oxidative leaching of copper from chalcopyrite. J Electroanal Chem 118:305-316.

Pradhan D, Kim DJ, Chaudhury GR, Sohn JS, Lee SW. 2010. Dissolution kinetics of complex sulfides using acidophilic microorganisms. Mater Trans 51:413-419.

530 Sandström , Shchukarev A, Paul J. 2005. XPS characterisation of chalcopyrite 
531 chemically and bio-leached at high and low redox potential. Miner Eng 18:505-515.

533 Sasaki K, Nakamuta Y, Hirajima T, Tuovinen OH. 2009. Raman characterization of 534 secondary minerals formed during chalcopyrite leaching with Acidithiobacillus 535 ferrooxidans. Hydrometallurgy 95:153-158.

Sillitoe RH. 2010. Porphyry copper systems. Econ Geol 105:3-41.

Sohn HY. 1979. Fundamentals of the kinetics of heterogeneous reaction systems in extractive metallurgy. In: Sohn HY, Wadsworth ME, editors. Rate Processes of Extractive Metallurgy. New York: Springer. P 1-51.

Stott MB, Watling HR, Franzmann PD, Sutton D. 2000. The role of iron-hydroxy precipitates in the passivation of chalcopyrite during bioleaching. Miner Eng 13:1117-1127. limitation improves bacterial leaching of chalcopyrite. Biotechnol Bioeng 78:433-441. 
550 Vilcáez J. 2015. On the mechanism of chalcopyrite bioleaching with thermophiles. Aust J

551 Earth Sci 2:1-4.

552

553 Viramontes-Gamboa G, Peña-Gomar MM, Dixon DG. 2010. Electrochemical hysteresis

554 and bistability in chalcopyrite passivation. Hydrometallurgy 105:140-147.

555

556 Viramontes-Gamboa G, Rivera-Vasquez BF, Dixon DG. 2007. The active-passive 557 behavior of chalcopyrite. J Electrochem Soc 154:299-311. 


\section{Figure 1.}

560 Changes in $\mathrm{Fe}^{2+}$ concentrations (a) and redox potentials $\left(E_{\mathrm{h}}\right)(\mathrm{b})$ during growth $(\mathrm{c})$ of each of four different Fe-oxidizers (Sb. acidophilus YTF1 (O, O) / Sb. sibiricus N1 with At. caldus KU. Sterile controls $(+, \quad \times)$ were run in parallel. Cell densities in the samples were determined by counting the cells of At. caldus $\mathrm{KU}$ and the other Fe-oxidizer with which it was combined. Solid lines indicate addition of $0.01 \%$ yeast extract. Broken lines indicate no yeast extract addition. Data points are mean values from were smaller than the data point symbols.

\section{Figure 2.}

Changes in total soluble $\mathrm{Cu}$ concentrations (a), $E_{\mathrm{h}}$ values (b), total soluble $\mathrm{Fe}$ concentrations (c), $\mathrm{Fe}^{2+}$ concentrations (d), $\mathrm{pH}$ values (e) and cell densities (f) during bioleaching of chalcopyrite concentrate. Mixed cultures contained At. caldus KU plus one 
577 of all bacterial cells in a sample. Data points are mean values from duplicate cultures.

578 Error bars depicting averages are not visible in some cases as these were smaller than the 579 data point symbols. "+YE" indicates addition of $0.01 \%$ yeast extract.

Figure 3.

Relationship between the normalized redox potential ( $E_{\text {normal; }}$ open symbols) and dissolution of $\mathrm{Cu}$ (solid symbols on solid lines) and Fe (solid symbols on broken lines) (inoculated at $1 \times 10^{7}$ cells $\mathrm{mL}^{-1}$ ) was used in mixed cultures with S-oxidizing At. caldus symbols.

\section{Figure 4.}

Relationship between the $\mathrm{Cu}$ leaching rate and the $E_{\text {normal }}$ value. The plots originated from mixed culture containing At. caldus KU plus one of the following Fe-oxidizers; $S b$. 

leaching rate of 2.2, likely resulted from rapid oxidation of chalcocite/covellite (accumulated before day 14 ) triggered by a jump in the $E_{\text {normal }}$ level at day 14 (Figure $3 \mathrm{c}$ ).

601

\section{Figure 5.}

$\mathrm{X}$-ray diffraction patterns and the color change of original chalcopyrite concentrate and

bioleached residues in mixed cultures containing At. caldus KU plus Sb. sibiricus N1

collected on day $2,7,12,21,26,31,38,55$, or 70. C; chalcopyrite (ICSD 2518), P; pyrite

(ICSD 633289), J; potassium jarosite (ICSD 166801), S; elemental sulfur (ICSD 412326).

608

\section{Figure 6.}

610 XPS spectra of $\mathrm{Cu} 2 \mathrm{p}$ (a) and $\mathrm{S} 2 \mathrm{p}$ (b) of chalcopyrite concentrates bioleached in mixed 611 cultures containing Sb. sibiricus N1 and At. caldus KU. Samples were collected at day 2, $6127,12,21,26,31,38$, and 55. Peak positions corresponding to original chalcopyrite $(\mathrm{Cu}$ $2 \mathrm{p}_{3 / 2}=932.4 \mathrm{eV}, \mathrm{Cu} 2 \mathrm{p}_{1 / 2}=952.3 \mathrm{eV}, \mathrm{S} 2 \mathrm{p}_{3 / 2}=161.4 \mathrm{eV}, \mathrm{S} 2 \mathrm{p}_{1 / 2}=162.5 \mathrm{eV}$

614 Ghahremaninezhad et al. 2013) are indicated by vertical grey bars. Peak positions 
615 corresponding to sulfate $\left(\mathrm{S} 2 \mathrm{p}_{3 / 2}=168.7 \mathrm{eV}, \mathrm{S} 2 \mathrm{p}_{1 / 2}=169.9 \mathrm{eV}\right.$; Klauber et al. 2001) are

616 indicated by grey broken lines. The doublet S $2 p$ peaks $(161.4 \mathrm{eV}$ and $162.5 \mathrm{eV})$ reflect

617 the occurrence of monosulfide and disulfide (Ghahremaninezhad et al. 2013). The shift

618 (to higher binding energies) of $\mathrm{Cu} 2 \mathrm{p}_{3 / 2}$ and $\mathrm{Cu} 2 \mathrm{p}_{1 / 2}$ peaks originating from chalcopyrite

619 was likely the result of a differential charging effect.

620

$621 \quad$ Figure 7.

622 Kinetic modeling of chalcopyrite bioleaching in mixed cultures containing At. caldus KU plus the following Fe-oxidizers; Sb. acidophilus YTF1 (•) / Sb. sibiricus N1

Acidiplasma sp. Fv-Ap ( $\mathbf{\Delta})$ / Acidiplasma sp. Fv-Ap (+YE) ( $) /$ Am. ferrooxidans ICP

$(+\mathrm{YE})(\diamond)$. Sterile controls $(\times)$ are also included. The rate-limiting step was assumed to be

(a) surface chemical reaction or (b) diffusion through product film. Linear lines were

drawn where $\mathrm{R}^{2}$ values were calculated to be $>0.97$. Day 0 plots were excluded to

chalcopyrite concentrate.

Table 1.

632 Elemental composition of chalcopyrite concentrate used in this study. 
634 Table 2.

$635 \mathrm{R}^{2}$ and $k$ values calculated using the kinetic model of surface chemical reaction and 636 diffusion through product film. 


\section{Acknowledgement}

638 Chalcopyrite concentrate was kindly provided by JX Nippon Mining \& Metals. Sb.

639 acidophilus strain YTF1 and Acidiplasma sp. strain Fv-Ap were kindly provided by Prof.

640 D.B. Johnson (Bangor University, UK). The XAFS experiments were performed at 641 Kyushu University Beamline (Saga-LS /BL06) with the proposal No. of 2016IK003 and 642 2016IIK013. We would like to thank Mr. Kazuhiko Shimada (Department of Earth and 643 Planetary Sciences, Kyushu University) for his technical support with the EPMA analysis.

644 Y.M. is thankful for financial assistance provided by the Kyushu University Advanced 645 Graduate Program in Global Strategy for Green Asia. 